\title{
Suture-related keratitis following cataract surgery caused by methicillin-resistant Staphylococcus aureus
}

This article was published in the following Dove Press journal:

Clinical Ophthalmology

20 March 2010

Number of times this article has been viewed

\author{
Ahmad B Tarabishy' \\ Thomas L Steinemann ${ }^{2}$ \\ 'Cole Eye Institute, Cleveland Clinic, \\ Cleveland, OH, USA; ${ }^{2}$ Cornea and \\ External Eye Disease, MetroHealth \\ Medical Center, Case Western \\ Reserve University, Cleveland, \\ $\mathrm{OH}$, USA
}

\begin{abstract}
A 54-year old-man presented with a two-day history of severe pain and decreased vision. Examination revealed a corneal ulcer associated with a loose suture from cataract surgery done approximately two years ago. The suture was removed and the patient was started on topic antibiotic treatment with cefazolin and gentamycin. Cultures revealed methicillin-resistant Staphylococcus aureus (MRSA). The antibiotic regimen was changed to include vancomycin but the ulcer continued to progress. Three days later, the ulcer had perforated and an emergent corneal patch graft was performed. To our knowledge, this is the first reported case of suturerelated MRSA keratitis after uncomplicated clear corneal cataract surgery.
\end{abstract}

Keywords: keratitis, MRSA, suture, staphylococcus aureus

\section{Case report}

A 54-year-old man presented to the eye clinic complaining of left eye pain for two days. His symptoms began two weeks prior with foreign body sensation which escalated to severe eye pain that interfered with sleep. He also noted purulent discharge, photophobia, redness, and blurred vision. There was no recent history of eye trauma or contact lens wear.

His past medical history was significant for uncomplicated clear cornea incision cataract surgery in his right eye in June 2002 and in his left eye in February 2005. A 10-0 nylon suture was placed in the clear cornea wound of his left eye intraoperatively out of concern for a possible small wound leak. A YAG laser capsulotomy was performed on the right eye in March 2007. He was not using any eyedrops.

On examination, his best correct vision was 20/25 right eye and 20/100 left eye. There was mild eyelid erythema and swelling on the left side and moderate diffuse injection of the left eye. Slit-lamp examination was remarkable for a $3 \mathrm{~mm}$ peripheral corneal ulcer with a stromal infiltrate (approximately 30\% thickness). Within the ulcer bed there was a broken corneal suture. The anterior chamber was deep, with a $10 \%$ hypopyon. A posterior chamber lens implant was centered in the capsular bag. Media haze prevented detailed examination of the vitreous and fundus. A B-scan ultrasound was performed with no evidence of vitreous opacities.

The broken suture was removed under direct slit-lamp visualization, placed in thioglycollate broth, and sent for culture. The ulcer was then swabbed with calcium alginate swabs and sent for gram stain and bacterial and fungal cultures. The patient was started on topical fortified antibiotics, cefazolin $50 \mathrm{mg} / \mathrm{mL}$ and tobramycin $14 \mathrm{mg} / \mathrm{mL}$, alternating every 30 minutes.
Correspondence: Thomas L Steinemann Professor of Ophthalmology, Cornea and External Eye Disease, MetroHealth Medical Center, Case Western Reserve University, 2500 MetroHealth Dr, Cleveland, OH 44109, USA Email tsteinemann@metrohealth.org 
Over the next two days, the hypopyon resolved, but corneal stromal thickening and haze persisted. Initial culture results revealed heavy growth of Staphylococcus aureus. Susceptibility testing demonstrated methicillin resistance, but the organism was sensitive to gentamycin and vancomycin. The cefazolin was discontinued, and vancomycin $50 \mathrm{mg} / \mathrm{mL}$ was started.

The next day the patient complained of worsening pain. Vision was hand motion. There was peaking of the pupil toward the periphery; a pigmented spot in the center of the ulcer representing an iris plug (Figure 1). A Seidel test was positive. The following day, the patient was taken for an emergent corneal patch graft and lateral tarsorraphy. Cultures taken intraoperatively were negative. Postoperatively, the patient was treated with $\mathrm{Zymar}^{\circledR}$ four times daily and bacitracin ointment at bedtime.
Approximately one month postoperatively, the best corrected vision in the left eye was 20/30. The ocular surface and patch graft were intact (Figure 2).

\section{Discussion}

Corneal sutures are sometimes used in cataract surgery to improve wound apposition and to prevent postoperative wound leaks. Although the exact incidence is unknown, suture-related keratitis following cataract surgery appears to be a rare event. ${ }^{1}$ There is conflicting evidence whether suture placement decreases the risk for postoperative endophthalmitis. ${ }^{2-4}$ Most of the data regarding suture-related keratitis come from the literature on penetrating keratoplasty. In this population, suture-related infection occurs in approximately $2-3.3 \%$ of eyes after a median of $21.5-30.8$ months. Risk factors for the development of infection include loose

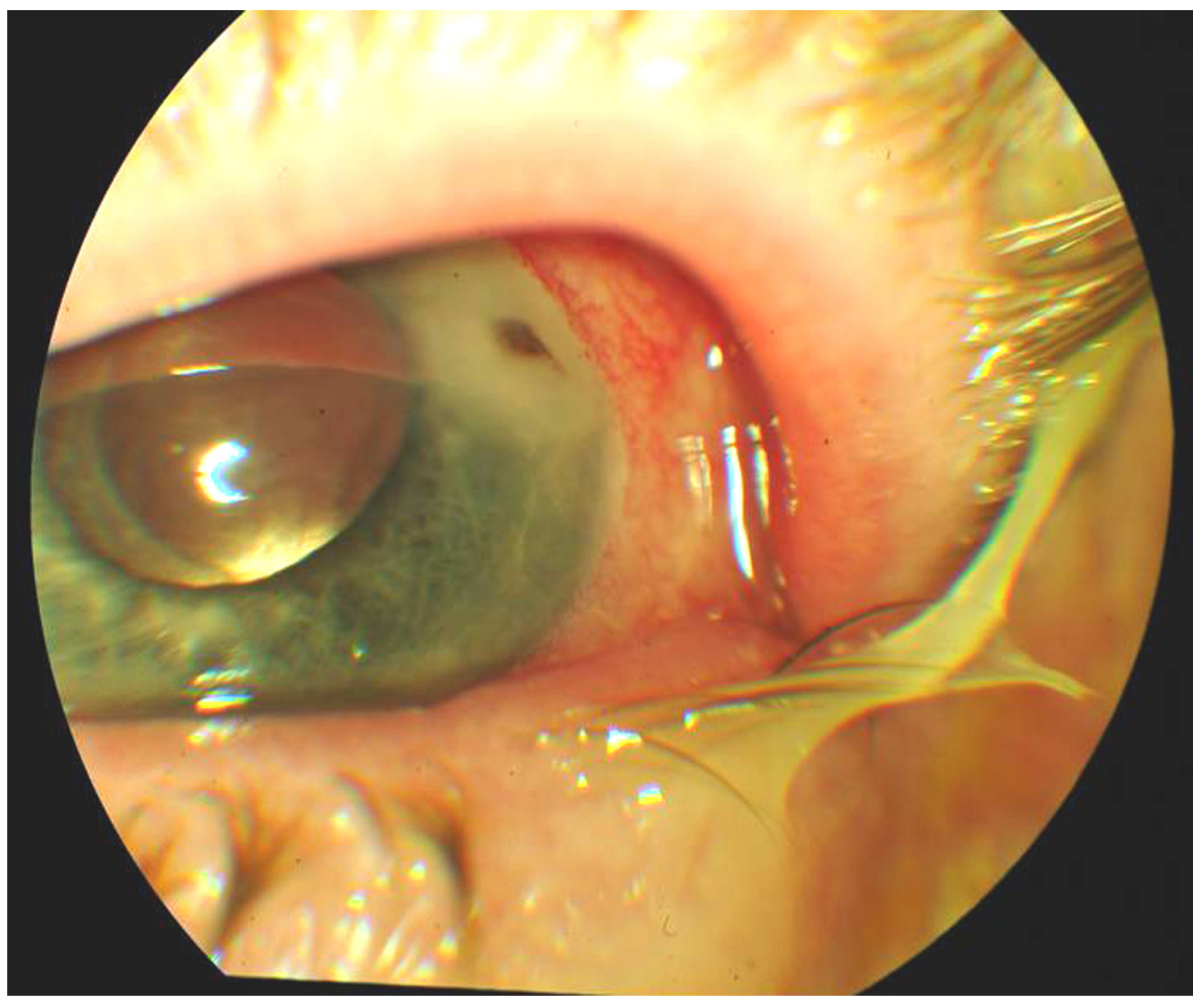

Figure I Image of cornea three days after presentation. A small iris plug is present in the center of the ulcer signifying a corneal perforation. 


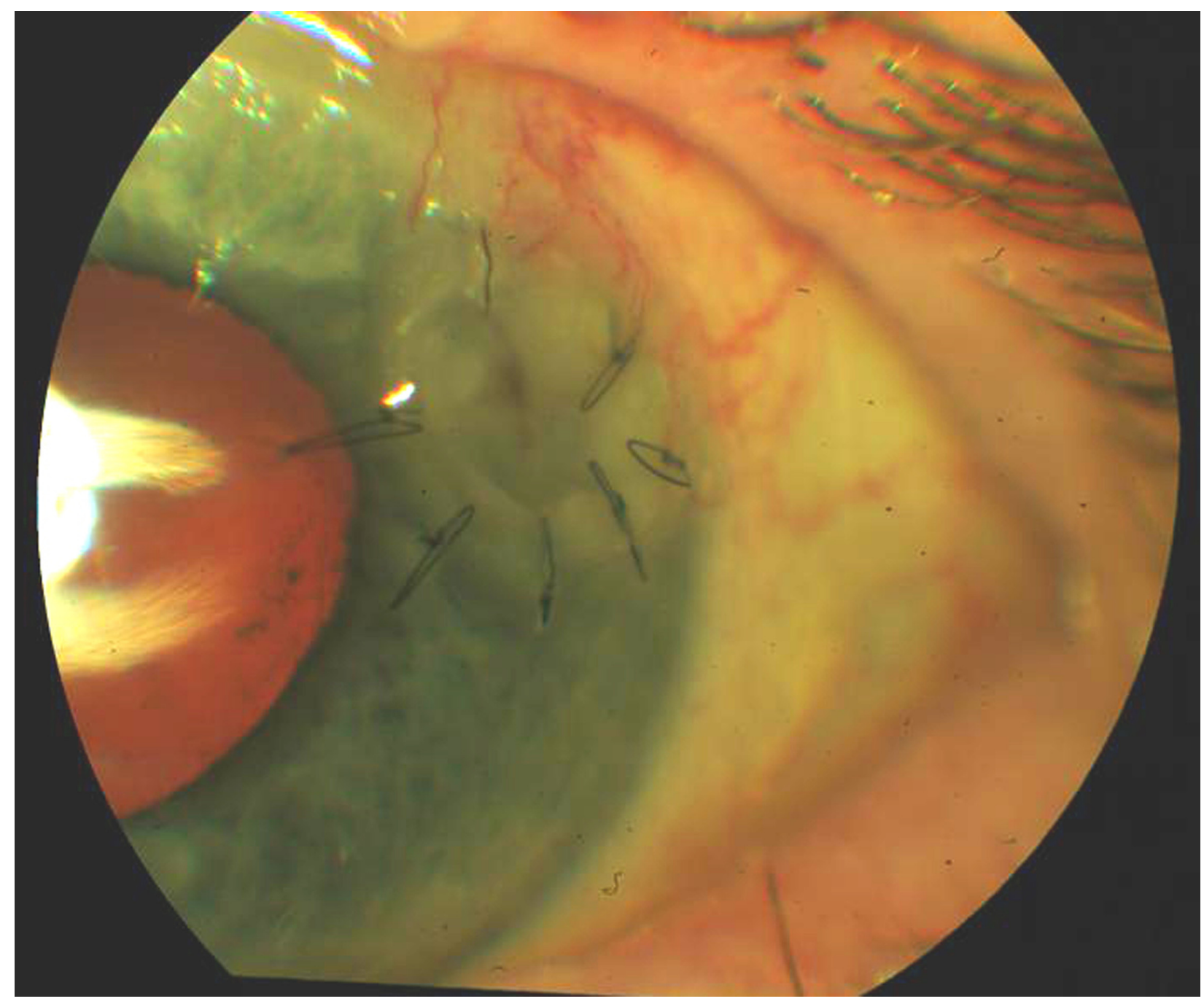

Figure 2 Appearance of cornea approximately one month postoperatively. The patient's best corrected vision was 20/30.

or broken sutures, corticosteroid use, persistent epithelial defect, contact lens use, keratoconjunctivitis sicca, and a history of herpes simplex virus keratitis. ${ }^{5}$

The ideal timing for suture removal following cataract surgery is unknown. Loose or broken sutures are a risk for suture abscess and should be removed. Lee et al describe three patients who developed suture-related infections up to 33 months after clear corneal cataract surgery, including one patient with methicillin-resistant $S$ aureus (MRSA). ${ }^{6}$ Suture removal itself may pose a risk for endophthalmitis. Culbert and Devenyi reported three patients who developed endophthalmitis soon after suture removal following cataract surgery. ${ }^{7}$

Endophthalmitis is usually classified into exogenous (typically occurring postoperatively or after trauma) and endogenous (usually occurs in patients with bacteremia or sepsis). It is important to recognize that the spectrum of organisms found in exogenous endophthalmitis tends to differ from that in endogenous endophthalmitis, although coagulase-negative Staphylococcus is the most frequent organism recovered in both types. If endophthalmitis is present, then empiric treatment with intravitreal antibiotics should be tailored according to the clinical scenario. ${ }^{8}$

MRSA is increasing in ocular and nonocular infections. ${ }^{9}$ MRSA can be divided into healthcare-associated (HA-MRSA) and community-associated (CA-MRSA) strains, based on clinical and epidemiologic characteristics. ${ }^{10}$ HA-MRSA is found in hospital or nursing home patients with severe infections, such as bacteremia or pneumonia, is associated with resistance to multiple antibiotic classes, and with increased mortality. ${ }^{11}$ CA-MRSA is associated with infection in patients without risk factors for HA-MRSA and is generally susceptible to non-beta-lactam antibiotics. ${ }^{12} \mathrm{CA}-\mathrm{MRSA}$ is the most common cause of soft tissue infections presenting to emergency departments in the US. ${ }^{13}$

Methicillin resistance in CA-MRSA infection is conferred by the presence of the staphylococcal cassette chro- 
mosome (SCCmec) Type IV plasmid, and can frequently be distinguished from HA-MRSA by a USA300 pattern with pulse-field gel electrophoresis. The patient's wife worked at the hospital as a registered nurse, but the isolated organism was not tested for the USA300 strain.

MRSA is also increasingly seen in ocular infections. Freidlin et al reported an increase in MRSA among 916 ocular $S$ aureus isolates from $4.1 \%$ in 1999 to $16.7 \%$ in $2006 .{ }^{14}$ Similar trends were noted by Marangon et al and Asbell et al in centers across the US. ${ }^{15,16}$ Among ocular isolates, there are also increasing high rates of resistance of $S$ aureus strains, including methicillin-sensitive strains to fluoroquinolones. Among MRSA isolates, resistance to fluroroquinolones, including fourth-generation agents such as gatifloxacin and moxifloxacin, approaches $85 \%{ }^{8,13}$ MRSA has been reported in association with postoperative wound ulceration following clear cornea cataract surgery without the use of a suture. ${ }^{17}$

This case report illustrates the importance of extended followup after cataract surgery, and timely suture removal from clear cornea wounds. In patients who develop infectious complications, urgent recognition and prompt referral is critical to optimal outcomes. It is also important to recognize the increasing incidence of antibiotic resistance in ocular $S$ aureus infection, and its implications for appropriate treatment.

\section{Disclosures}

This work was supported by an unrestricted grant from Research to Prevent Blindness. The authors report no conflicts of interest in this work.

\section{References}

1. Cameron JA, Huaman A. Corneoscleral abscess resulting from a broke suture after cataract surgery. J Cataract Refract Surg. 1994;20:82-83.
2. Thoms SS, Musch DC, Soong HK. Postoperative endophthalmitis associated with sutured versus unsutured clear corneal incisions. $\mathrm{Br} J$ Ophthalmol. 2007;91:728-730.

3. Wallin T, Parker J, Jin Y, et al. Cohort study of 27 cases of endophthalmitis at a single institution. J Cataract Refract Surg. 2005;31:735-741.

4. Cooper BA, Holekamp NM, Bohigian G, Thompson PA. Case-control study of endophthalmitis after cataract surgery comparing scleral tunnel and clear-corneal wounds. Am J Ophthalmol. 2003;136:300-305.

5. Jeng BH, Oxford KW, Abbott RL: Infections after penetrating keratoplasty. In Krachmer JH, Mannis MJ, Holland EJ, editors: Cornea, 2nd ed. Philadelphia, PA; Elsevier: 2005.

6. Lee BJ, Smith SD, Jeng BH. Suture-related corneal infections after clear corneal cataract surgery. J Cataract Refract Surg. 2009;35:939-942.

7. Culbert RB, Devenyi RG. Bacterial endophthalmitis after suture removal. J Cataract Refract Surg. 1999;25:725-727.

8. Lemley CA, Han DP. Endophthalmitis: A review of current evaluation and management. Retina. 2007;27:662-680.

9. Asbell PA, Colby KA, Deng S, et al. Ocular TRUST: Nationwide antimicrobial susceptibility patterns in ocular isolates. Am J Ophthalmol. 2008;145:951-958.

10. Klevens RM, Morrison MA, Nadle J, et al. Invasive methicillinresistant Staphylococcus aureus infections in the United States. JAMA. 2007;298:1763-1771.

11. Cosgrove SE, Sakoulas G, Perencevich EN, et al. Comparison of mortality associated with methicillin-resistant and methicillin-susceptible Staphylococcus aureus bacteremia: A meta-analysis. Clin Infect Dis. 2003;36:53-59.

12. Fridkin SK, Hageman JC, Morrison M, et al. Methicillin-resistant Staphylococcus aureus disease in three communities. $N$ Engl $J$ Med. 2005;352:1436-1444.

13. Moran GJ, Krishnadasan A, Gorwitz RJ, et al. Methicillin-resistant S. aureus infections among patients in the emergency department. NEngl J Med. 2006;355:666-674.

14. Freidlin J, Acharya N, Lietman TM, et al. Spectrum of eye disease caused by methicillin-resistant Staphylococcus aureus. Am J Ophthalmol. 2007; 144:313-315.

15. Marangon FB, Miller D, Muallem MS, et al. Ciprofloxacin and levofloxacin resistance among methicillin-sensitive Staphylococcus aureus isolates from keratitis and conjunctivitis. Am J Ophthalmol. 2004; 137:453-458.

16. Asbell PA, Sahm DF, Shaw M, et al. Increasing prevalence of methicillin resistance in serious ocular infections caused by Staphylococcus aureus in the United States: 2000 to 2005. J Cataract Refract Surg. 2008;34:814-818.

17. Chiang RK, Rapuano CJ. Recurrent methicillin-resistant Staphylococcus aureus wound ulcer after clear-cornea cataract surgery. CLAO J. 2002;28:109-110.
Clinical Ophthalmology

\section{Publish your work in this journal}

Clinical Ophthalmology is an international, peer-reviewed journal covering all subspecialties within ophthalmology. Key topics include: Optometry; Visual science; Pharmacology and drug therapy in eye diseases; Basic Sciences; Primary and Secondary eye care; Patient Safety and Quality of Care Improvements. This journal is indexed on Submit your manuscript here: http://www.dovepress.com/clinical-ophthalmology-journal

\section{Dovepress}

PubMed Central and CAS, and is the official journal of The Society of Clinical Ophthalmology (SCO). The manuscript management system is completely online and includes a very quick and fair peer-review system, which is all easy to use. Visit http://www.dovepress.com/ testimonials.php to read real quotes from published authors. 